\title{
BUSINESS MODELS FOR ONLINE EDUCATION
}

George Lorenzo

Educational Pathways

\begin{abstract}
Nine institutions-Colorado State University, Dallas County Community College District (DCCCD), Duquesne University, Georgia Institute of Technology, University of Central Florida, The University of Illinois at Springfield, University of Massachusetts Lowell, University of Michigan, University of Georgia—share information about their business models.
\end{abstract}

\section{KEYWORDS}

Targets of Opportunity, Self-sustaining, Course Development, Quality Assurance, Return on Investment, Responsibilities, Grant Proposal

\section{COLORADO STATE UNIVERSITY}

Location: Fort Collins, CO

Student Population: 27,973

Type of Institution: 4-year public and above (Land Grant)

Carnegie Classification: Doctoral/Research Universities-Extensive

Distance Education Unit:

Continuing Education

Self-Funded Independent

Websites:

Colorado State Continuing Education: http://www.learn.colostate.edu

Based on Interviews with Al Powell, program director, certificates, online and independent learning and Debi Colbert, program director, distance degrees

Colorado State Division of Continuing Education (DCE) is a self-supporting unit that develops and delivers distance education degrees and certificate programs, credit and noncredit courses, and custom training for businesses and industry. DCE has been offering distance education since 1967 and adult education programs in Denver for more than 20 years. DCE currently serves about 13,000 students each year in both face-to-face and distance programs.

\section{A. Targets of Opportunity}

"We are still showing signs of developing a business model, but if you want to characterize ours, you can call it targets of opportunity," says Al Powell. These targets can come from an outside entity, such as an industry in need of special training through a certificate program; internally from a department that identifies a need to provide access to more students, such as a water hydrology program that attracts an international audience; a state agency in need of employee training; or community college graduates 
seeking four-year degrees. When such targets present themselves, "two things happen more or less simultaneously," says Powell. "We start talking to the academic department involved, and we try to figure out a way to conduct market research that will tell us what the prospect for success really is for a program. We do not have a fixed format. We do develop a spreadsheet to predict the costs of development and delivering the program, as well as the projected revenues. Some times we do pay for development and other times we don't.”

\section{B. Responsibilities of Academic Units and DCE}

The academic departments within the university initiate requests for courses to be converted, or developed from scratch, to the distance learning format and are fully responsible for course development. DCE helps with coordination efforts, providing suggestions on what may need to be included inside a curriculum based on their market research. However, sales and marketing are DCE's two primary responsibilities, along with providing registration services to students.

Technical support is provided by the institution and quality control of course development is handled through the Office of Instructional Services, a university-wide organization responsible for providing media and instructional technology support for instruction, outreach, and other purposes for faculty, staff, and graduate teaching assistants.

The gathering of retention data is currently in a development phase. Overall quality control of courses and programs "is determined by the fact that we are a university and our faculty are teaching," Powell explains. Beyond that, quality control, in terms of the way courses are conducted and the types of media used, is facilitated through a student-government-mandated survey that is an evaluative process. "The quality control measures tend to be more student-evaluation-based, with feedback to the faculty members and expectations that faculty want to do better every time around.”

The responsibility for hiring faculty also rests with the departments, but DCE does jump in. "I worked with several different departments to get adjunct faculty to teach courses; I have found faculty and received the department's approval for these faculty to teach courses,” says Debi Colbert.

\section{Overall Structure of DCE}

DCE is comprised of 35 employees divided into six divisions: Enrollment Services, Online \& Distance Learning, Denver Programs, Northern Colorado Programs, Administration, and Continuing Education Initiatives. Powell and Colbert fall under the Online \& Distance Learning division. Director Rick Simpson oversees the entire DCE staff.

Program directors are responsible for various business units within each division. "Each program director has a chunk of business that they tend to specialize in, but we do move back and forth and support each other as needed," notes Powell. For example, Powell happens to have an extensive background in agriculture, so he handles an Agriculture and Range Science distance degree program, which would normally fall under the purview of Colbert, who is distance degrees program director.

Program directors are also responsible for sales. "We double that way," Powell explains. "As our programs grow, it is predictable that we will be hiring a direct sales staff.” Two years ago, however, DCE was forced to lay off two sales professionals and a marketing manager for fiscal reasons. 


\section{Non-Credit Offerings}

DCE non-credit offerings are in a relatively large rebuilding phase. Historically DCE has offered a wide variety of non-credit distance education courses through outside vendors who supply a host of courses, ranging from bookkeeping and paralegal certification to graphic design and SAT/ACT preparation courses.

Recently DCE signed a contract with the state of Colorado to become the continuing-education- approved entity for all state employees, both at a distance and in face-to-face classes. Additionally, DCE will soon be offering reduced-priced, non-credit enrollment options inside many of its for-credit online offerings. "There are plenty of courses we offer that have value," says Powell. "For instance, we have a four-credit greenhouse management course, and half of the people taking it are in the greenhouse industry. If we provide that as a non-credit course at a slightly reduced tuition rate, we think we will considerably increase enrollments and revenues.”

\section{E. Fiscal Responsibilities}

Under Colorado state law, most continuing education units operate as enterprise units that pay their own bills that are generated by tuition dollars. "The models vary," says Powell, "but basically the way we pay our bills is when we enroll a student, that tuition is split between us and the department —or us, the instructor, and the department."

DCE currently pays faculty an average of $\$ 3,000$ to develop online courses. However, both Colbert and Powell say that there are many instances where faculty will come to them with a good portion of their course already converted to the online mode of delivery. These faculty typically do not seek any compensation, or they might need a relatively small amount of money in the $\$ 1,000$ dollar range to pay for graduate student assistance to fine-tune their course to a fully online modality.

"We are getting close to having one kind of split," adds Colbert. "Currently financial agreements with departments are a little scattered, but we have to pay our overhead to the university, and we have to make a certain amount of money to keep our doors open. However, we try to give the majority of the revenues back to the department.”

In general, the business model at DCE is one in which program directors run their own micro businesses and have a good deal of autonomy. Says Powell: "The director (Rick Simpson) delegates a great deal of authority to each one of the program directors. Rather than imposing a financial plan from the top, what he has done is told us that based on what our gross is, we know the percentage of overhead the university gets, and we know the percentage of overhead the administrative operations and continuing education get. For example, I have five different spreadsheets, and I can quote you percentages off any of them-one for the Agricultural Education degree I run, one for the Rangeland Ecology degree I run, etc. I have separate spreadsheets for online courses, correspondence courses and telecourses. So each program director knows exactly what their programs cost and knows exactly what percentage they are getting from any particular type of course. We all work under the directive that we bring these plans forward to the fiscal officer and the director. And every program that we have must be set up as a financially sustainable model." 


\section{DALLAS COUNTY COMMUNITY COLLEGE DISTRICT (DCCCD)}

Location: Dallas County, Texas

Student Population (7 colleges): 82,641

Type of Institution: 2-year public

Distance Education Unit:

R. Jan LeCroy Center for Educational Telecommunications

Self-Funded College

Websites:

Dallas TeleLearning: http://telelearning.dcccd.edu/

Dallas TeleCollege: http://dallastelecollege.dcccd.edu

Based on Interview with Pamela Quinn, Assistant Chancellor, DCCCD and President, LeCroy

Center

About 80 people from the LeCroy Center for Educational Telecommunications are responsible for running two organizations-Dallas TeleLearning and Dallas TeleCollege-that provide distance education courses, programs and services through the Dallas County Community College District (DCCCD).

The entire operation is self-sustaining. "The LeCroy Center does not receive tax dollars directly like a college; we have to be entrepreneurial to exist," says Quinn.

\section{A. Dallas TeleLearning}

The birth of Dallas TeleLearning came in 1972 when DCCCD produced an American Government telecourse that enrolled 399 students. Today, Dallas TeleLearning has grown into one of the leading suppliers of programming for the Public Broadcast System (PBS) Adult Learning Service, and more. In excess of 40,000 students enroll in telecourses through PBS each semester. However, Quinn explained that PBS Adult Learning Service is dissolving at the end of September 2005, and the LeCroy Center is diversifying its products and services to meet market demands on a variety of different fronts. In addition to being used by the DCCCD's seven colleges, Dallas TeleLearning courses, which can be delivered on broadcast and cable television, on CD-ROM and DVD, or as streaming video, are leased on an annual fee basis to institutions across the country.

Dallas TeleLearning courses are by no means ordinary. These are extremely sophisticated interactive video and computer-based productions that can cost up to $\$ 1.5$ million each to produce. "We have had a very large penetration with up to 1,200 different colleges and universities using our product over the years," says Quinn. "Probably $60 \%$ of those colleges are two-year schools, and $40 \%$ are four-year schools.”

TeleLearning courses are primarily college credit-bearing, transfer courses in the general education area. "We know what the most popular courses are across the country that all freshmen and sophomores are taking. That is the market we have gone after-everything from English to business to history and health and nutrition,” says Quinn. 
"The business plan we use for course development is very high end and detailed, with the end result being a product that can be used by a lot of institutions and then scalable within an institution. Multiple faculty can teach the same course."

\section{B. How Telecourses are Produced}

Faculty course developers are typically hired from within the DCCCD. They serve as content experts for two years but do not appear in the videos. These faculty go on leave from their home colleges and are paid their same annual salaries by Dallas TeleLearning.

Courses are developed and produced by a team of script writers, producers, programmers, and instructional designers. "We interview the best professors all across the country on whatever the topic is," says Quinn. "The faculty member is working with script writers to develop the script (they also write a student guide for the course). When we are producing these video tapes, our crews are literally flying around the country. If we are interviewing someone who is an expert on the Civil War and they are based at the University of Tennessee, then we go to the University of Tennessee.”

The courses are made up of documentaries, professional interviews and narration, along with interactive learning activities. A textbook is also included in the package. "We partner with major publishers in the development of the course,” says Quinn. A standardized, well-known textbook typically supplements the video. The two year course production cycle starts with the planning out of course content creation and a production schedule over the first nine months. The next nine months are the actual production of the course, and the remaining six months are used for editing and pulling everything together into a final product.

The academic integrity of the Dallas TeleLearning courses starts with a curriculum committee that is developed for every course which approves every phase of the production cycle and ensures that academic objectives are met. Plus Dallas TeleLearning has a national advisory committee comprised of faculty members from around the country who meet twice each year in Dallas. "They fly in and our team here goes over everything with them, and we get feedback and input into whether or not we are doing the right thing, or if we need to change anything," says Quinn.

Dallas TeleLearning is also responsible for marketing and leasing these courses through its business and marketing departments.

\section{Win-Win}

The DCCCD college that loans out its professor for two years gets the course at no charge to offer to their students. "We work collaboratively," adds Quinn. "They get credit for everything we create, so the benefit goes back to the college. Also, for an experienced faculty member who has spent years in the classroom, this two-year assignment provides a wonderful way for them to update their knowledge and meet some of the key academicians in their field. They travel, and they get rejuvenated. Our colleges totally support that because it is such a great staff development program for them as well, since these faculty members return to the colleges as better classroom teachers.” 


\section{Dallas TeleCollege}

The Dallas TeleCollege is an entirely different operation that also comes under Quinn's authority. The staff at the LeCroy Center for Educational Telecommunications is responsible for recruiting students to the online virtual campus of the DCCCD. Any course delivered through the Dallas TeleCollege is the equivalent of the same course taught on campus. All courses appear on an official transcript as being offered by one of the seven accredited DCCCD colleges.

In addition to recruiting students to the TeleCollege, a support staff at the LeCroy Center is responsible for the entire district's online registration help desk, as well as for providing technical support to both oncampus and online students and faculty.

All tuition dollars generated by the Dallas TeleCollege go to the TeleCollege. "We keep all the tuition," says Quinn. "It is a special formula that our system has allowed us to develop. They did not put us into the normal funding formula that our campuses are in, so we came up with something a little different. It is an internal process that puts us more on the entrepreneurial side. When you enroll students, you get money; when you don't enroll students, you don’t get money."

The seven colleges get the contact hours that are generated from TeleCollege students, which are, in turn, reported to the state for state-funding purposes.

"We recruit locally and nationally to bring in students to add to the enrollment base," adds Quinn. "We reach out. We have had students enroll in the TeleCollege from all 50 states, and we have students who have enrolled from five continents. So we really have reached out on a worldwide basis, and that is where we are generating new enrollments for our colleges-plus we have a lot of [on-campus] students who are taking distance learning courses.”

\section{E. Other Revenue Streams}

In addition to the many district-wide distance learning administration, technology infrastructure and instructional support service functions housed at the LeCroy Center for Educational Telecommunications, the Center also provides educational institutions, business and industry, and governmental agencies with a variety of contractual support services. These include leasing of conference rooms; downlinking of teleconferences; leasing of production facilities, use of instructional design and production staffing; delivery of educational programs by microwave and satellite; and educational telecommunication consulting services.

"I don't want to be dependent on one revenue stream," says Quinn. "So we continually look for new ways to support our students and colleges. And, of course, we are non-profit, and any additional revenue goes into our fund balance, which allows us to create courses and products when we see the need.” 


\section{DUQUESNE UNIVERSITY}

\section{Location: Pittsburgh, PA}

Student Population: 9,722

Type of Institution: 4-year private, not-for-profit

Carnegie Classification: Doctoral/Research Universities---Intensive

Distance Education Unit:

School of Leadership and Professional Advancement

Self-Funded College

Website:

School of Leadership and Professional Advancement: http://www.leadership.duq.edu/

Based on Interviews with Kelley Maloney, Director of Marketing and Communication, School of Leadership and Professional Advancement (SLPA); Ben Hodes, Dean of SLPA; and Boris Vilic, Director of Technology for SLPA

Duquesne University's School of Leadership and Professional Advancement (SLPA) is one of 10 schools at the university. It was formerly the Division of Continuing Education. SLPA offered its first online courses in 1996. Its first fully online degree program, a master's in Leadership and Liberal Studies, was launched in 1999. SLPA now delivers an undergraduate degree (several concentrations), one graduate certificate, and five graduate degrees online. Approximately one-third of SLPA students are now earning their degrees entirely online.

\section{A. How Programs Get Started}

In terms of how programs are developed and launched, SLPA conducts in-depth research with industry professionals to determine a program's viability. For example, "We started a bachelor's degree in Humane Leadership in conjunction with the Humane Society of the United States, and we worked with them to develop the curriculum and make sure it worked for their target population," says Maloney. The program is designed for individuals working in animal care and control facilities across the United States and is intended to provide targeted, specific knowledge that will support their career goals in animal advocacy and shelter management.

For another new degree program, a new master's in Sports Leadership, SLPA conducted focus groups and gathered information from sports professionals and managers. They discovered a need for educational opportunities for those working in the professional sports industry to build skills in handling ethical and legal matters, strategic marketing issues, and leadership training for contemporary sports challenges.

"Before we can offer a program, it has to go through our academic council, which is comprised of all the deans, the provosts, the librarian, the IT director, all the major academic players on the campus," says Vilic. "They look at the program and determine if it is feasible or not feasible and if it should be housed in our school or not in our school. Once the academic council grants approval for the program, we sometimes have to go to the state for approval, and we also have to work with our budgeting office to make sure that the program gets funded. There are steps for both the academic council and budget management side that we have to accomplish to make sure we get the requisite funds to start the program.” 
Hodes explains that programs start through "a very serious balancing act between the political environment in the university, the mission of the university, our strengths, our capacity, and what market needs exist. When it comes to new program development, some universities stumble and have to make a lot of sacrifices, and it compromises their effectiveness in the market. We are fortunate. We run much more like a business.

"On the program development side, there is not a lot of response lag time; while we are very thorough in curriculum development, there is not an extensive curriculum committee review; a lot of it is juggling and getting ideas that can fit in amidst all those variables. We have been very lucky in the sense that we have had far more success than we have had failures. We also believe that in order for it to ultimately succeed in the market, it has to succeed academically. So, there is far more attention being paid, although it is in the early stages, to learning outcomes. Also one of the dimensions that is often overlooked in distance learning is this whole issue of customer service. How do you serve a population that can't come into your office? There are a lot more difficult challenges to delivering customer service.”

\section{B. Quality Assurance}

To help guarantee a high quality online teaching and learning experience, SLPA uses a faculty evaluation instrument called the Teaching Effectiveness Questionnaire (TEQ). Instructors at Duquesne University are required to have their students provide feedback on their teaching through the TEQ. It is administered near the end of the semester by a staff member, not the course instructor. The responses are anonymous, and they are not available to the instructor until well after the course grades have been submitted. In addition, Noel Levitz conducts student satisfaction surveys for SLPA. "We try to get as much feedback as we can directly from the customer. And more important, we try to act on the issues that arise," says Hodes.

Team leaders within disciplines are responsible for working with faculty to make sure that the quality is where it needs to be academically, and an assistant dean of academic programs gets involved with any quality issues on a day-to-day basis. Team leaders also advise students in matters related to credit transfer and other issues - "the typical department chair responsibilities," says Vilic, who serves as team leader for technology courses. They are also responsible for course staffing, which includes identifying prospective faculty members. "Once I identify them, I have to get them approved by the assistant dean and the dean," he adds.

Additionally, SLPA recently started a new online faculty support service called "eCoach.” Here Rita Marie Conrad and Judith V. Boettcher-national experts in the area of instructional design and online teaching - are available to answer any questions a faculty member might have regarding online instruction in SLPA.

Faculty must also live up to a contract and online teaching standards "to really accommodate the unique needs of our students," says Vilic. For example, online faculty must respond to students within 48 hours, post at least four substantive messages each week, and grade students' work in a timely and effective fashion. "We have been doing this for a long time and have data on what works and does not work online," Vilic adds.

About 50\% percent of the faculty who teach in the SLPA programs come from the other schools on campus, and some are team leaders. These full-time Duquesne faculty teach classes on an overload basis unless otherwise assigned by their department chairs. The rest of the faculty are adjuncts who are 
professionals in their chosen fields. Faculty are also given a "small stipend" to develop new online courses.

\section{Fiscal Feasibility}

Vilic adds that every new program is evaluated for fiscal feasibility after three years, and to be financially feasible means that there is some profit from the program—it cannot be generating losses.

\section{GEORGIA INSTITUTE OF TECHNOLOGY}

Location: Atlanta, GA

Student Population: 16,841

Type of Institution: 4-year public

Carnegie Classification: Doctoral/Research Universities-Extensive

Distance Education Unit:

Georgia Institute of Technology Distance Learning \& Professional Education

Self-Funded Independent

Websites:

Georgia Institute of Technology Distance Learning \& Professional Education:

http://www.cdl.gatech.edu

The Global Learning \& Conference Center at Technology Square:

http://www.glcc.gatech.edu/

Based on Interview with William Wepfer, Vice-Provost for Distance Learning \& Professional Education \& Professor of Mechanical Engineering

The Georgia Institute of Technology (GIT) Distance Learning \& Professional Education (DLPE) is housed in GIT's new Global Learning \& Conference Center (GLCC) at Technology Square, a facility that features over 32,000 square feet of high-tech meeting space, including a wireless environment and the ability to send and receive programs worldwide from any of the conference center's 27 meeting rooms.

DLPE consists of four programmatic areas: distance-learning, professional education, the Language Institute, and conferencing and space rentals within the GLCC. DLPE's distance education offerings include seven graduate degree programs in engineering and a master's in Medical Physics (jointly with Emory University). A College of Architecture Building Construction master's program at a distance will be launched in January 2006.

Georgia Tech began providing distance-delivered master's degree programs in 1977 in response to the needs of local employers. The first three degrees offered were in electrical, mechanical, and aerospace engineering. The course content was captured via video cameras and shipped via video tapes and thus our heritage is rooted in the TV broadcast culture, says Wepfer. The other programs (industrial engineering, civil engineering, environmental engineering, and operations research) have been added in distance format beginning in the early 1990s. Medical Physics began as a distance-delivered Health Physics degree in the 1980s and was recently reconfigured to meet the needs of a newly-emerging field. 
GIT also offers a good number of non-credit professional education and personal enrichment courses both on campus at its Global Learning \& Conference Center and off-site at locations through-out the US. DLPE is "starting to dabble in" the distance-delivery of such continuing education courses," says Wepfer.

DLPE is also the home of GIT's Language Institute, a successful on-campus English as a Second Language program that is beginning to develop two online courses on written business communication and accent reduction.

"I am a business unit that has to come out in the black," says Wepfer.

\section{A. Delivery Format}

Off-campus students can choose from video classes, Internet courses (mechanical engineering and electrical and computer engineering), or classes in a combination of the two formats.

Video cameras record faculty lectures and student-faculty interaction during regular 15-week (semester) graduate classes. The videotapes, CD-ROMs or DVDs, and supporting course materials are sent to offcampus students for viewing. Students interact with faculty via telephone, fax, and electronic mail. Student-to-student and student-to-faculty interaction occurs using bulletin boards and the threaded discussion capabilities of WebCT.

\section{B. Building a Better Backend}

DLPE is currently in a transition and infrastructure-building phase to better manage its growth. "We are in the process of converting our entire operations-credit and non-credit," says Wepfer. This includes going live with a new SunGuard Banner enterprise system by this coming winter, followed by a redesign of its website. I want to get the architecture of the system right within the university's database system, and then, assuming the Banner conversion goes well, we will start to revise our web interface to integrate more marketing and an easier-to-use interface.”

Additionally, coming from a heritage of video-taped lectures, DLPE recently converted to streaming media this fall. All captured course content is now available via Video on Demand (VoD). DLPE also adopted fax server technology to replace its outdated fax paper transmission processes.

DLPE also provides streaming media capture and support for course content exchanged between the Atlanta and savannah campuses for four undergraduate engineering programs. This is all done synchronously via high-bandwidth Internet connectivity.

\section{Responsibilities}

Most of the courses offered by DLPE consist of video-taped on-campus live courses put inside the WebCT course management system. Other courses consist of lecture modules taped in a studio. DLPE is responsible for capturing, coding, digitizing and archiving these live courses and modules. "We are the students' arms and legs," says Wepfer. "The other thing we do is provide the academic units with marketing assistance. On the non-credit side, this is absolutely essential. On the credit side, you always have a dialogue with the academic units. They think they know everything about marketing, so you have to sort of finesse that a little bit." 
DLPE is also involved with business planning and the gathering of market survey data.

\section{Business Planning and Business Model}

"We have to be involved in business planning and providing market survey data," says Wepfer. Any program that wants to go online has to submit a request-for-approval to the State Board of Regents of the University of Georgia System. In addition to filling out rudimentary forms for the Board, Wepfer has recently started to incorporate a version of the Michigan State University Office of MSU Global's Business Planning and Costing Model (BPCM) that is used for the development and implementation of online degree and certificate programs. The BPCM is comprised of five templates and a Program Costing Model (PCM) that have been developed since MSU Global was established in 2000. The templates help to streamline the entire online degree/certificate planning, development and implementation process. (See the Sloan-C Effective Practice "Business Planning and Costing Model Streamlines Development and Implementation Process” at http://www.sloan-c.org/effective/details5.asp?CE_ID=59.)

\section{E. Becoming More Proactive}

Although DLPE does not get heavily involved with curriculum development, Wepfer said he is trying to get his unit to be "very proactive. The legacy of this unit is that we were reactive. We are not doing that anymore." The adoption of the MSU BPCM will help "develop protocols, so as units come to us, they will have a clear set of expectations of what we need, and what they need to do, and what needs to happen to make a program work.”

GIT does have a Center for the Enhancement of Teaching and Learning (CETL) that provides instructional technologies and designers for the development of distance courses. "When we partner with units, we try to point out to them how critical it is to have an instructional designer, and we do everything we can to get them to involve CETL.” Wepfer says that his unit currently pays for CETL services, but he predicts DLPE will eventually hire its own instructional design staff in the future.

In relation to monitoring learning effectiveness, "we have an awful lot of input on the technical quality of what goes out," says Wepfer. As a Vice Provost; Wepfer reports to the Provost. In addition, Wepfer is a member of the Georgia Tech Council for Institutional and Academic Program Review and Accreditation. "That carries some weight," he adds. "We don't micro manage what is going on in the classroom, but student and customer services are critically important. If there is a problem, my office hears about it ... We also look at the course evaluations on the academic side, so we try to sort of do the bully pulpit.”

\section{F. Financial Considerations}

DLPE keeps $79 \%$ of the tuition revenue generated by the distance degree programs. The remaining $21 \%$ gets returned to the units, and most of that money filters back to the faculty as non-compensatory discretionary money. "The faculty members get some tangible benefit in recognition that it is an additional work load," says Wepfer. "We have some courses that might have 40 students on campus and another 15 or 20 at a distance. We have some faculty members in some of those units pounding on our door. They want to do distance courses partly because they like to do it, but they also like it because they get some discretionary money for traveling to conferences, or to hire grad students, or to buy some equipment. I have one mechanical engineering colleague that has about 20 distance learning students and she will get about $\$ 7,500$ in extra revenue to spend on her program. For our faculty this is an appropriate incentive that works.” 
Wepfer also points out that the DLPE trys to obtain investment money for putting courses and programs online. For instance Sloan-C awarded GIT a grant (matched by the University System of Georgia) to put its Mechanical Engineering program online.

"The other thing I am challenged with is the new building [GLCC], and so I have to generate \$2.5 million per year to pay debt service," says Wepfer. "I am contributing a fraction that has been growing each year we have been in the facility. In the past, I did not have to pay debt service, and I would use a lot of that money for investment in new programs. So right now I am investment dry. I can make some, but I have to be very selective in terms of what I invest in.”

\section{UNIVERSITY OF MASSACHUSETTS LOWELL}

Location: Lowell, MA

Student Population: 11,089

Type of Institution: 4-year public and above

Carnegie Classification: Doctoral/Research Universities-Intensive

Distance Education Unit:

Division of Continuing Studies \& Corporate Education

Self Funded Independent

Websites:

UMass Lowell Continuing Studies \& Corporate Education: http://continuinged.uml.edu/

UMass Online: http://www.umassonline.net/

Based on Interview with Jacqueline Moloney, Dean of Continuing Studies and Corporate Education

With more than 65 years of service to adult learners, primarily in Massachusetts and New Hampshire, UMass Lowell's Division of Continuing Studies \& Corporate Education (CSCE) serves one of the largest student populations in northern New England, receiving approximately 20,000 enrollments annually. Nine years ago, the division started to offer online courses, beginning with four courses that were not part of any degree or certificate program. Today, it offers four fully online undergraduate degrees, five fully online graduate degrees, and 14 fully online undergraduate and graduate certificate programs.

\section{A. Disciplined and Rigorous Business Plan Approach}

In Massachusetts, continuing education must be self supporting and operate at no cost to the commonwealth. "We have to account for, in an audit sense, all of our expenses, including overhead and reimbursement to the campus," says Moloney. So the division's business model, which was set up during its early years and developed over time, revolves around a business plan approach that includes the development costs of online programs, forecasts on what these programs should generate in revenue, and calculations with regard to when and how much return on investment ought to be realized.

Moloney calls her business plan approach "very disciplined. We go through a pretty rigorous process. We meet with the departments and deans, and we come up with a business plan for each program, which I submit to the Chancellor as part of my annual budget and strategic plan. Included in that plan is our cost for developing courses, new markets, and money needed by the department to support the initiative. For 
example, we will often include the cost for teaching assistants and clerical assistance. In one or two cases we have even supported faculty lines.”

\section{B. Responsibilities}

In addition to business planning, CSCE is responsible for course development, faculty support and development, front-line technical support for students, and program-specific marketing plans and services. It is also part of UMass Online, the University of Massachusetts system's (Amherst, Boston, Dartmouth and Lowell) portal to online programs. The Division of Continuing Education \& Corporate Education pays a $10 \%$ assessment out of its gross revenues to participate in UMass Online.

Another part of the financial formula includes paying for People Soft software as part of the division's overhead. Moloney added that she works with the university's Office of Enrollment Services, meeting with them once a month to review the impact of any decisions related to online student services.

CSCE is also responsible for price setting. "We have some capacity to do market-driven tuition setting," Moloney said, "but generally we try to keep it consistent with what the state-supported programs charge for tuition. That is set by the state legislature and is a function of what they and the board of trustees think is affordable."

When talking about the level of control CSCE has over the hiring of faculty and the sustaining of learning effectiveness and overall program quality, Moloney said that final decisions are made more jointly than in the past between the academic units and the Division of Continuing Education \& Corporate Education executive staff.

\section{Successful Example}

With regard to program development and business planning, in general, Moloney points to an online master's degree program in Education Administration that was launched in the fall of 2002 as an example of how the processes work, although there are different models that can be used, depending on the program under development. "They [the on-campus master's in Education Administration program] had failing enrollments, and I had been talking to them about moving the program online,” Moloney explains. "Our team here of marketing people, course development people, and curriculum experts met with graduate school of education faculty and the dean. We had planning sessions with up to 25 people participating in these sessions. We reviewed everything from program development to the targeted audience. We developed a five-year budget, projecting costs, growth revenues and tuition.”

In calculating gross revenue, the formula was based on the program starting with 75 to 100 students at a growth rate of $25 \%$ for five years. The tuition was calculated at $\$ 1,000$ per year, and the direct costs of instruction, marketing, and course development was calculated at $\$ 10,000$ per course plus an overhead charge for continuing education to provide all the student services. (This year all continuing-educationmanaged student services were transferred over to the institutional level. "We developed this cutting edge response system for students; they took our staff and our automated services and collapsed them into the day school,” says Moloney.)

"We also factored in the department's cost for engaging in this activity, depending on the department's needs, [i.e., they might need a teaching assistant to field inquiries from prospective students]," says Moloney. 
Ultimately the master's in Education Administration program was modeled after the university's oncampus degree program, which is designed around the frameworks required for earning Massachusetts state certification for principals, assistant principals, supervisors, and/or directors. Initially there were some tentative feelings about whether or not the program would succeed. There are a significant number of competing schools and colleges of education in Massachusetts offering master's degrees. However, "from the beginning we have not only sold almost every class we have offered, but in many cases we have had to add extra sections," says Moloney.

Tuition and fees are affordable, based on in-state tuition rates. Student enrollment is capped at 22 per class to encourage maximum student-instructor interaction, and technology support for novice online learners was ensured. The Graduate School of Education (GSOE) benefited by receiving funding from net revenues for teaching assistants, clerical support and adjuncts. As a result of the success in this program, the GSOE has launched 3 new graduate online degrees in high demand areas.

During the program's first year of operation, approximately 300 students, about $75 \%$ of whom were already enrolled in the on-campus program, took online courses. "We have had very high levels of satisfaction and high return rates," says Moloney. "We have students who are enrolled in this program who are ten miles away and never came to school here" because they could not fit face-to-face classes inside their already busy schedules. In addition to increasing enrollments, GSOE has increased the number of graduates from this program, from a low of 7-10 per year to a graduating class of 26 last year.

Another innovative feature of this program has been the faculty's deep involvement in planning and development. The Deans of GSOE and CSCE; the faculty; and a team of course developers, program developers and marketing specialists from CSCE; meet regularly to discuss progress towards benchmarks based on Sloan-C's 5 pillars. This process created a feedback loop on the quality of all aspects of the program that resulted in outstanding evaluations by faculty and students and provided an excellent model for building collaboration between academic programs and continuing education.

Online education has enabled this program to make leadership opportunities more accessible to larger numbers of highly qualified people; by nurturing, challenging and inspiring these candidates all within the online environment to fill some of the most demanding roles in our society. The program's theme, "Education for Transformation," has "gone live online."

\section{About ROI}

With regard to return on investment formulas, Moloney says that the rule of thumb is to at least reach a break-even point by the end of any new program's third year. Depending on the program, along with such factors as how the program fits in with UMass Lowell's brand and mission, $15 \%$ above the break-even point after the third year is preferable, and "this is consistent with the goals that the Chancellor has set for continuing education," adds Moloney. The master's in Education Administration program reached its break-even point by the end of its second year of offerings. 


\section{UNIVERSITY OF CENTRAL FLORIDA}

Location: Orlando, FL

Current Student Population: 45,000

Type of Institution: 4-year public and above

Carnegie Classification: Doctoral/Research Universities-Intensive

Distance Education Units:

Central Administration: Information Technologies and Resources

Three primary units relative to distance education are:

Center for Distributed Learning

Course Development and Web Services

Research Initiative for Teaching Effectiveness

Subsidized Service Unit-Overhead Funded

Websites:

Online@UCF: http://online.ucf.edu

Information Technologies and Resources: http://www.itr.ucf.edu/

Center for Distributed Learning: http://online.ucf.edu/cdl/

Course Development and Web Services: $\underline{\text { http://www.cdws.ucf.edu/ }}$

Research Initiative for Teaching Effectiveness: http://pegasus.cc.ucf.edu/ rite/

Based on Interviews with Joel Hartman, vice president and CIO, Information Technologies and Resources and Steven Sorg, director of the Center for Distributed Learning

For the purpose of easy nomenclature, we refer to the combined primary units responsible for distance education at the University of Central Florida (UCF) as Online@UCF.

UCF is a rapidly expanding metropolitan research university in the growing city of Orlando. As campus growth continued at a rapid pace, UCF administrators realized, about 10 years ago, that effective growth and management of fully online programs and courses (what UCF calls "W" courses for Web-based), as well as the effective growth and management of blended courses (what UCF calls " $\mathrm{M}$ " courses for Mixed-Mode) could help infuse new teaching and learning efficiencies, as well as save on valuable physical space, well into the future.

A conversation with Hartman and Sorg reveals a mindset centered around the growth and management of providing an increased number of fully online programs and blended courses that ultimately have a considerable impact on the entire UCF campus. This impact, along with the strategic institutional planning it promotes, is backed up with solid data that has been collected and analyzed since UCF started offering distance education courses in 1996 to increase access opportunities for a specific group of students who were spread across the state.

Online@UCF engages more than 75\% of the faculty and tens of thousands of students both on an off campus. Online@UCF offers 6 undergraduate degree completion programs, 9 graduate degree programs and 10 graduate certificates, plus $227 \mathrm{~W}$ courses and $142 \mathrm{M}$ courses every semester from all academic areas. Online@UCF also offers extensive resources and support services for students over the Web. 


\section{A. An Activity of the Institution}

Hartman describes Online@UCF as an "activity of the institution-not an activity of a piece of the institution. All of the academic colleges to a greater or lesser extent are offering online programs and/or blended learning courses. So, you can think about this as a fully integrated activity that coexists alongside face-to-face delivery, and that involves the same academic planning procedures, and the same kinds of goals and strategies, although they tend to be different with online because of unique opportunities. It is the same faculty and the same programs, in most cases. It is basically a core business of the institution."

\section{B. Where It All Starts and Grows}

Online@UCF “coordinates program planning; internal and external relationships with colleges, departments and programs; accreditation; and policy as it relates to the academic side of this endeavor," says Sorg. "To that end, we hold planning meetings with each of the college deans, the director of our regional campus system, and any others that are appropriate-all of whom have desires and needs that are in part fulfilled by having online courses, online programs, or blended courses.”

Each fall and spring term Online@UCF holds a meeting with the deans of all the UCF colleges, who invite their department chairs and any other administrators, such as assistant deans. According to Sorg, these two meetings address what various departments need to develop online courses and programs. "It starts with these meetings, and then there is a lot of activity in the background that I conduct with them, trying to elicit information that will help with planning," says Sorg. Planning includes establishing a timeline for online support, coordinating with the program itself and the department chair which faculty members are going to need online course development support and training, and when the program is estimated to go online so that students can enroll. An optional promotional service that includes the production of brochures is also provided by Online@UCF to help the departments recruit students.

\section{Not a Business Planning Model}

Overall, Online@UCF does not operate under any business models, per se. "It is more of a planning process," says Sorg. "They [colleges or departments] contact me or get referred to me and I initiate the process of clarifying what it is they want to do, for whom, what's the time frame, what are the courses involved, who are the faculty-and then we try to get them into the queue (for training and course development) so that their goals, plans and timelines are met by our support services.”

Financial incentives to individual faculty members to conduct their course development work are provided in the form of a $\$ 2,000$ stipend or a one-course release from their teaching assignment during the term that they are going through faculty development. They are also given new notebook computers if they are full-time faculty members. If they are essential adjuncts needed to deliver the program, they are provided with the stipend alone.

\section{Other Meetings}

Two more regularly scheduled meetings drive the development of online and blended learning environments at UCF on a continuous basis. One is a monthly meeting of a Distributed Learning Advisory Group that consists of the lead Online@UCF staff, the Vice Provost of the UCF regional campus system, the Dean of Graduate Studies and the Dean of Undergraduate Studies. Additional staff from across campus, such as the Continuing Education Department, are invited each month. Recent discussions, for instance, have revolved around providing more general education courses online to 
reduce bottlenecks in various courses.

Another is a weekly meeting of an Enrollment Management and Planning Group, which is a broader group consisting of the aforementioned educators as well as staff from the Admissions Office, the Registrar's Office, Institutional Research and Planning, and other offices and departments across campus. "We talk about how to manage the growth we have at this university, including online learning as one of the key strategies for managing and planning growth," says Sorg. "We think we have turned the corner here. While it [online learning] has always been in the back of people's minds, it is now right up front."

\section{E. Collecting Data}

In addition, Hartman stresses how Online@UCF has, since its inception, consistently collected data and generated reports based on that data in order to address important issues, questions and concerns related to any online learning initiatives. "Our motto is lacking data, anecdote wins," he says. In other words, isolated incidents that people have experienced, seen or heard can often grow into perceived truths that typically are not accurate. Therefore, you have to collect a large enough sample of data over a long enough period of time to offset inaccuracies and prove or explain real trends and developments.

For example, Sorg and his staff at the Center for Distributed Learning, with the help of the Research Initiative for Teaching Effectiveness, are responsible for producing a reliable bank of information based on facts that can ultimately paint an accurate picture of the true scope and scale of UCF's online learning initiatives. With that in mind, Sorg publishes a document titled "UCF Access, Quality and Efficiency through Online Learning," which is a part of a report about what kind, how much and where online learning is happening at UCF. Each term this report is shared with the college deans and chairs. "The idea is to share with them a spreadsheet in which all of the productivity data for each college is broken down by the different instructional modalities-everything from face-to-face to fully online courses and all the variations in between," says Sorg. "Since it is broken down by college, they can look and see in their own college what percentage of their activity is in certain modalities, what the productivity levels are, and where those productivities are being gained.”

A more specific example of how data collection and report production can address key issues and concerns was demonstrated by a project in which UCF's Data Mining Program and the Research Initiative for Teaching Effectiveness collaborated on an analysis of 1.2 million student responses to course/instructor evaluations given over several years. These evaluations are comprised of 16 questions, eight developed by the state and eight developed by UCF. According to Hartman, UCF online faculty were concerned that these questions fit more closely to face-to-face courses than online. Plus, faculty who were novice online teachers, still learning to master teaching online, were concerned that they might get lower student evaluations than their face-to-face colleagues, and thus suffer the consequences. The analysis, however, proved that faculty who taught online were, on average, rated excellent $14 \%$ more frequently than faculty who taught face-to-face. Plus, all 16 survey items tracked identically for both faceto-face and online courses. Hartman adds that, overall, helping to achieve success requires "collecting an enormous amount of information about activities and using that information to both inform others and for continuous improvement. We have made a significant number of changes and adjustments along the way based on a variety of feedback that has helped the effort adapt and fit the institutional needs.”

\section{F. What About Return On Investment?}

The colleges receive support for their online courses in exactly the same manner as they do for face-to- 
face courses. Because the overall institutional budget is tied to enrollment growth, there is great interest in accommodating student demand. Online@UCF has become a strategic resource for accommodating institutional growth.

Annual revenues from fully online students, inclusive of matriculation fees and state support, totaled more than \$23.5 million for academic year 2004-2005. As a return on the university's investment in online learning support resources, this represents an ROI of approximately ten-to-one. In addition, the cost of brick and mortar construction that has been avoided due to fully online and blended learning courses exceeds $\$ 4.5$ million.

\section{THE UNIVERSITY OF ILLINOIS AT SPRINGFIELD}

\section{Location: Springfield, Illinois}

Student Population: 4,396

Type of Institution: 4-year public

Carnegie Classification: Master's Colleges and Universities I

Online Unit:

Office of Technology-Enhanced Learning (OTEL)

Subsidized Service Unit - Overhead Funded

Websites:

Office of Technology-Enhanced Learning: http://otel.uis.edu/

UIS Online: http://otelportal.uis.edu/

Based on Interviews with Ray Schroeder, Director of OTEL and Shari McCurdy, Associate Director of OTEL

The University of Illinois at Springfield's (UIS) Office of Technology-Enhanced Learning (OTEL) began in 1997 with a grant from the University of Illinois system (comprised of three campuses: Chicago, Urbana-Champaign and Springfield) for the purpose of catalyzing the delivery of online learning. In addition to being supported institutionally through state appropriations, which have decreased in recent years, UIS OTEL has received more than \$3 million in grants since its inception, with the majority coming from Sloan-C (see listing of grants at http://online.uis.edu/info-click on "Grants" in right column). For example, it recently was awarded $\$ 1.2$ million from Sloan-C, matched with $\$ 400,000$ from the University of Illinois system president's office, to deliver eight new online degree programs.

In the fall of 1998, OTEL started to officially launch online courses through UIS Online, which is a part of the University of Illinois Online (http://www.online.uillinois.edu/) support system and a central source for information regarding the online degree programs, online courses and public service activities offered by the three University of Illinois campuses. UIS Online has grown enrollments by approximately 30\% each year since it started. UIS Online currently offers six fully online undergraduate degrees, three fully online graduate degrees, and two fully online certificate programs. Five additional degree programs have been approved and are being developed.

Along with these programs, UIS offers individual for-credit online courses and the U of I Online Making the Virtual Classroom a Reality (MVCR) classes. MVCR courses are designed to assist faculty who wish to move their classrooms online. UIS also participates in the Illinois Virtual Campus, an electronic 
catalog of online and distance learning courses available from nearly 40 colleges and universities in Illinois.

UIS Online does not offer any non-credit courses. OTEL's mission revolves around providing a host of services to UIS faculty, including pedagogical training; technological training; research and coursedelivery support. It also assists programs in moving curricula from campus-based to online delivery. Additionally, OTEL is responsible for investigating and acquiring software licenses that support its online learning efforts.

\section{A. Technology Fee}

To facilitate a continuous source of funding for OTEL, the UIS administration implemented a technology fee for all online courses. This fee, which is plowed back into online learning, has grown from \$15 per credit hour to \$25 per credit hour. Thirty percent of the technology fee (\$7.50) goes directly to OTEL. With approximately 2,700 enrollments this fall 2005 semester taking on average of 3.7 credit hours each, about $\$ 75,000$ from the technology fee will be generated for OTEL in one semester. This money is used to help defray the cost of software licensing fees. For example, in addition to funding Blackboard, OTEL supports such software as TurnitIn, Eluminate, and WebBoard. In addition, the fees help fund faculty development and support services for online students.

"I am a born-again believer in the idea of per-unit fees, because as the programs scale, your revenues scale, as well as your costs," says Schroeder, referring to the increased cost of software.

\section{B. How Programs are Started}

Since all UIS programs begin primarily through grant funding, UIS uses an RFP process to solicit its 40 departments that may want to move a program(s) online (see "Grant Proposal Development Guidelines" below).

"In each case we develop a business plan; it is really a simple process," says Schroeder. "How many students are you going to have? How is your program going to scale up, etc.? The decisions are made on the best demonstrated need and business plan. We normally map out four years, and we try to get a $100 \%$ cost recovery for the salaries of faculty members and for a program coordinator.”

Faculty are paid \$6,000 off-load to develop an online course. These faculty then teach these same courses on-load.

The UIS Provost is the final decision-maker as to whether or not a program ultimately goes online. This decision-making process is aided by recommendations made by an academic cabinet comprised of academic deans. Schroeder also contributes his input into this process when necessary.

\section{Program Coordinators}

The program coordinator is a half-time professional who serves as a basic front-gate admissions advisor who points prospective online students to the appropriate institutionally provided student services, such as registration and financial aid services, that will ultimately get them enrolled in a program. "The bulk of student services and support go through the program coordinator, and it just naturally flows that way because that is the first person they talk to," says McCurdy. "The program coordinators are the reason 
why students come to UIS-because they give them personal attention and help them through the program.”

\section{Tuition}

One of the reasons why UIS has consistently experienced a 30\% annual enrollment growth rate could be because out-of-state online students pay the same tuition as in-state online students, provided that they are accepted into a full program. They can't take advantage of in-state tuition rates if they enroll in nondegree courses.

\section{E. Who is Responsible for What}

As aforementioned, OTEL primarily supports faculty training and course development. The unit also manages the tools necessary for online learning and encourages related research and scholarship. Academic units are responsible for curricular development, hiring faculty, learning effectiveness, evaluations, assessments, etc.- - all managed the same as on-campus courses and programs.

The institution provides all the typical and necessary student services for students to get enrolled and stay in these programs from an administrative perspective. OTEL also offers support for such units as disability services and the center for teaching and learning with hardware, software and training to permit them to provide effective services to distant students.

\section{F. Informal Network Maintains Integrity}

UIS is a relatively small institution with an informal network that helps to maintain both academic and administrative quality. "We do a lot of informal things without direct line authority," says Schroeder. "We are all about service and access. We serve the faculty; we serve the students; we work for them." Schroeder is a veteran faculty member who has been teaching in the Illinois system since 1971. "I know what it is like to teach and what the faculty want, and that is the way you sell online learning to the oncampus people. You get the faculty excited about online learning at the grassroots. You don't tell them you have to teach online, you get them to want to teach online."

With regard to continuously maintaining the integrity of all UIS online programs, Schroeder says, "we have 200 some courses, and we usually hear early on from students when there are any problems in classes. If needed, I get involved with the students, then the faculty member, then the department head, then the dean. The primary mode of quality assessment is student evaluation. The very same evaluation used on campus, which is heavily weighted in the tenure and promotion process."

\section{G. Unfulfilled Potential}

Finally if there are any serious issues, overall, at OTEL and UIS Online, it's that they can't keep pace with their potential growth. "It is amazing to me that we could have 10,000 enrollments this semester," Schroeder claims. "We have 2,644 enrollments this morning, and that is without any substantial marketing. We are turning away people by not opening additional course sections. We simply are not scaling at the department level to meet the demand.” 


\section{H. Grant Proposal Development Guidelines}

The proposal should begin with a description of the program to be delivered. Any differences between the scope of the program as it has been delivered on campus and the proposed online degree should be clearly identified. The use of instructional methods other than online (e.g. blended courses) should also be described. The remainder of the proposal should address issues of educational and economic viability. Suggestions for appropriate documentation are offered below:

\section{Educational Viability}

The educational viability of the proposals will be evaluated by program committees, the college curriculum committees, the graduate and undergraduate councils, and, if necessary, by the Senate itself under their existing procedures and criteria. The proposal should include formal approvals from the appropriate program and college committees.

In this case, we would ask that particular attention be paid to the following items:

- That the program has clearly stated student learning outcomes and appropriate mechanisms in place for their assessment. Evidence of prior success with the implementation of an effective assessment program would be significant.

- A detailed multiyear course schedule that will allow both new online and existing students to progress towards the degree in a timely fashion. The schedule needs to be adequate for the number of students anticipated and the program needs to be committed to its delivery.

- A detailed schedule for the development and deployment of the courses required in an online format. Evidence of the program's commitment to online instruction would be helpful. A description of characteristics of the students the online program will serve. Admission criteria that will be used to select among applicants should be described.

- The extent to which arrangements have been made to provide courses required outside the major, if any.

- Issues of accreditation, if applicable. Is the program currently accredited? What will be the impact of online delivery on accreditation?

- Evidence that adequate plans have been made for advising and other support services required by the program's students.

\section{Economic Viability}

\section{Revenue}

- Total enrollment and credit hour projections based on the rate at which students will be admitted, the assumptions made about retention and the rate of progress towards the degree.

- Projections for tuition and fees charged. A rationale for differential tuition, if proposed.

- Evidence of student demand for the online program, accompanied by enrollment history for the existing program and any prior online offerings, if applicable.

- Total revenue projections based on the information above.

\section{Expenses}

A budget for the one-time grant funds to include course development and other startup expenses. (Typically ten $\$ 6,000$ course development stipends, plus $\$ 20,000$ for staff support.) 
An ongoing budget plan that would allow the program to be delivered indefinitely, to include:

- Projections for additional faculty required to support the multiyear course schedule as proposed for new online and existing students. Typically, new faculty would not teach entirely online, but rather would enable the program to share the responsibility for the new and existing offerings.

- Projections for support staff requirements and other operating budget requirements (e.g. equipment, marketing expenses, etc.).

- Projections for ongoing faculty development and curriculum development.

\section{Other General Considerations}

- The relationship of the proposal to UIS and/or IBHE priorities.

- Evidence of societal need, including employment prospects for graduates.

- Other materials as deemed appropriate by the proposing unit.

\section{UNIVERSITY OF MICHIGAN}

Location: Ann Arbor, MI

Student Population: 39,533

Type of Institution: 4-year public

Carnegie Classification: Doctoral/Research Universities-Extensive

Distance Education Unit:

Michigan Engineering Center for Professional Development

Self-Funded, College

Websites:

Michigan Engineering Center for Professional Development: http://cpd.engin.umich.edu/

Interdisciplinary Professional Programs: http://interpro.engin.umich.edu/

Based on Interview with Ed Borbely, Director, Michigan Engineering Center for Professional Development

The University of Michigan College of Engineering has a history of offering distance education courses dating back to the late 1960s when it delivered distance-education courses synchronously to remote locations via a microwave TV transmission system.

Today the University of Michigan Engineering Center for Professional Development (CPD), in partnership with a relatively new Interdisciplinary Professional Programs Office (InterPro) that was created two years ago, offers two fully online graduate degrees and courses toward three others: in Global Automotive and Manufacturing Engineering, Automotive Engineering, Integrated Microsystems, Pharmaceutical Engineering, and Manufacturing Engineering, as well as a graduate-level Lean Six Sigma Professional Certification Program. These credit-bearing programs, combined, enroll about 400 offcampus students, and growing. Another 400 on-campus students have the option of enrolling in these courses at their own discretion. 
CPD also delivers a good number of non-credit engineering professional-development "short courses," and certification programs that generate on average about 4,000 enrollments (not unique head counts) annually.

The for-credit graduate programs and the non-credit professional-development courses and certification programs are managed within two distinctly different business models.

\section{A. For-Credit Fully Online Graduate Programs}

The business planning for fully online credit-bearing graduate programs is rooted in an activities-based costing model implemented at the college level, says Borbely. "Costs have been estimated right down to the semester-credit level. Our distance-learning costs are a component of the tuition charged.” Bottomline is that, for the purposes of this costing model, CPD's break-even point comes at 2,400 credit hours each year. "That is across all of the credit courses we deliver," says Borbely. "After that, we are in a mode where there is money to invest and grow.”

CPD is responsible for the development and instructional design of online courses, as well as for all of the administrative and student-services elements, including technical support and marketing, needed to effectively deliver these programs. CPD's academic counterpart is InterPro, which "worries about all the things that an academic department normally worries about," says Borbely. InterPro was founded in 1998, and off-campus enrollments enable their existence because the revenues from distance learners make it possible to fund the appointment of faculty teaching courses that are vital to graduate professional programs. We would not be able to pay for that if we did not reach critical mass. In turn, we and offcampus student-customers are able to count on InterPro to produce what we need in the way of administrative support, teaching assistantships and getting faculty to participate.”

Faculty are paid one month's salary off-load for developing courses in these graduate-level programs, with the assistance of CPD, which is quite different from what they get paid for developing non-credit professional-development courses and certification programs.

\section{B. Non-Credit Professional Development Courses and Certification Programs}

The side of CPD that offers professional development has operated more like an independent, small business within the University of Michigan College of Engineering. "We speculate on the market potential for a given course the same way we would if we were renting hotel space in Chicago," Borbely jokes.

"We work with faculty directly to develop and produce the content, and each deal is unique. Of course, there are limits in terms of university policy on how and how much we can pay faculty. We produce the course, and typically the compensation for faculty involves a combination of some costs to develop the course-so they are compensated for developing the course-and a royalty scheme at the university that is modeled after the similar policies for licensing new technologies. A portion goes to the individual faculty member; a portion goes to their academic dept; and a portion goes to the College of Engineering. It's basically a third, a third and a third. You come back to break even, and then all profits or return on investment is divided in thirds." 
When asked how much faculty get paid for course development, Borbely said "it depends on the individual. We have a range to compensate them for their time, whether they are teaching in front of a classroom (many of these online courses include videotaped lectures that are streamed for viewing online by students) for a "short course," or whether they are spending a day, or a fraction of a day, developing a course. When it is a development effort, the same rate card applies, meaning we pay faculty on a scale from $\$ 1,500$ to $\$ 4,000$ a day.”

How much a faculty member is ultimately compensated can also be based on what the market will bare, adds Borbely. "A lot of it has to do with the perceived market potential for a course; it has nothing to do with how advanced the level of material is." In the end, the cost of faculty is rolled into the budget along with all of the outer expenses and overhead related to producing and delivering any given course.

Just like in the credit-bearing graduate programs, CPD provides all of the administrative and studentservices elements, including technical support and marketing services for the non-credit professional develop courses and certification programs.

In relation to quality control and learning effectiveness strategies, Borbely says that CPD has relied on a combination of feedback from its students and the corporations who enroll in these professional development courses on a volume basis. "It is a combination of direct feedback and aggregate feedback from corporate customers.”

Borbely adds that CPD's professional develop enterprise has been successful and that they "have plans to put a lot more online.”

\section{UNIVERSITY OF GEORGIA}

Location: Athens, GA

Student Population: 33,405

Type of Institution: 4-year public

Carnegie Classification: Doctoral/Research Universities-Extensive

Distance Education Units:

University System of Georgia Independent and Distance Learning

eCore: Georgia's College Core Curriculum Online

Subsidized Service Unit - Overhead Funded

Websites:

University System of Georgia Independent and Distance Learning:

http://www.gactr.uga.edu/idl/index.phtml

eCore: Georgia’s College Core Curriculum Online: http://www.gactr.uga.edu/ecore/

Based on Interviews with Nancy Thompson, Head, Independent and Distance Learning/eCore, and Brad Cahoon, Director for the Division of Distance Education

The University of Georgia Center for Continuing Education is responsible for two distance education units in the University System of Georgia: Independent and Distance Learning (IDL) and eCore. 


\section{A. Independent and Distance Learning}

IDL has its roots in a long history of correspondence courses offered by the University System of Georgia institutions dating back to pre World War II. In the late 1940s these were centralized in the Center for Continuing Education on the Athens campus. Today IDL offers about 140 credit-bearing "self-paced" courses, with about 60 of these courses being offered in an online format, and the remainder being offered in a print-based format.

The University System of Georgia offers students higher education options at 34 colleges and universities throughout the state, providing a wide range of academic programming, including certificates, associate, baccalaureate, master's, doctoral and professional degrees.

IDL students do not have to be admitted to the University System of Georgia to enroll, though many current University System of Georgia students supplement their on-campus classes with IDL courses. Students can register at any time for IDL courses. Tuition for IDL courses is $\$ 152.00$ per semester hour, with the exception of those University of Georgia students who are classified as nonresident (out-of-state) students. Out-of-state students who wish to receive resident credit for IDL courses must pay $\$ 661.00$ per semester hour.

In each course, there are lesson assignments corresponding to assigned readings in required texts or materials. These assignments are submitted consecutively via mail or online to IDL, where they are logged before being forwarded to an instructor. If any students need to contact the instructor, a note can be included with a lesson, or they may contact him or her via e-mail or phone.

The maximum time allowed to complete an IDL course is nine months, though students are strongly encouraged to finish these courses in less time. Students must be enrolled in the course at least eight weeks, and all required lessons must be submitted and completed before taking a final exam.

\section{B. IDL Business Model}

"We have perhaps an unusual program financially in that we retain all of the tuition revenue from students who take these (IDL) courses, and that revenue stays here and more than offsets the cost of payroll and operations," says Cahoon. "The program generates a surplus that is used to fund additional course development and for other programs here in continuing ed."

Planning of any new courses is the responsibility of IDL. "It is a collective decision based on our perceptions of what our market will support, and sometimes faculty here at the university or from other institutions will approach us with a special interest for creating a course. Some of those projects get off the ground, and some don't." Cahoon explains that this decision-making process is more of a "rule of thumb" approach, but "we need to quantify this a little bit more rigorously, and we have, in terms of assessing the financial performance of courses. We have a lot of data about the enrollment of each course and what it is contributing financially.”

Faculty interested in developing a course submit one lesson and an overview of the course. If approved, they will earn $\$ 1,800$ for developing a complete course. A team of web designers from the University of Georgia Center for Continuing Education Department of Web Instructional Development builds out all of the IDL courses in a standardized format, although there is variability in the way faculty write and present their content. Faculty are the final authorities on what content ultimately goes inside their courses. Faculty 
are paid another $\$ 1,500$ per course for a full revision when necessary.

The responsibility of learning effectiveness and quality control of IDL courses, which are basically replicas of University System of Georgia face-to-face courses, are shared with the academic units, says Cahoon. "Our goal is to make sure that learning outcomes are equivalent to face-to-face classes."

IDL hires faculty based on academic department recommendations and approval. However, if an IDL faculty member is not up to speed and his or her evaluations continue to slide, "we relieve them of their responsibility," Cahoon says. "That is the ultimate control that we have."

IDL is also responsible for student services through its student services unit, which consists of three representatives who help to register and advise students. However, 70 to $80 \%$ of IDL students are University of Georgia students who take one or two courses and receive the full benefits of student services at their home campus.

\section{C. eCore}

eCore-short for electronic core curriculum-allows University System of Georgia students the opportunity to complete their first two years (the "core" curriculum) of their collegiate careers in an online environment. eCore consists of online freshman- and sophomore-level courses designed, developed, taught, and supported by faculty and staff from the University System of Georgia. Students register for eCore courses through one of six affiliate institutions that offer the courses and becomes the student's home institution.

The first eCore courses were offered in 2000. "The main difference between these courses and IDL courses is that these are cohort courses running on a regular semester schedule," says Cahoon. "The instructional design is more sophisticated because it allows for the fact that students can be involved in group discussions and other forms of group activities.”

A unit called Advanced Learning Technologies, that is directly supported by the State Board of Regents, put together teams of faculty from different institutions within the system to develop a common curriculum of eCore courses. With the help of the University of Georgia Center for Continuing Education Department of Web Instructional Development a standard set of 25 eCore courses were developed.

Instructors for eCore courses are recruited and hired by eCore from all the 34 institutions in the University System of Georgia. "Our biggest challenge right now is the recruitment of enough faculty for the number of sections we want to offer," says Cahoon.

Student services, including advisement, are handled by each of the six affiliate institutions. "One thing we are going to do this September is pull all the eCore advisors here for a two-day meeting to go through every single service that should be provided to students and find out what is happening on all these campuses," says Thompson. "We know that some campuses are doing a better job than others."

\section{D. eCore Business Model}

"We are absorbing all the cost of the eCore program, because we compensate faculty, and we create the courses. We also do the technical administration of the course in terms of setting up the course sections, offered in WebCT Vista," says Cahoon. 
eCore pays \$1,200 per-credit-hour to the faculty member's institution as teacher pay. The institution then pays its faculty whatever they would normally be paid for teaching off-load or on-load. "Some institutions do have it as part of the regular teaching load, and, for $\$ 3600$, they are able to hire two part-time faculty members to teach two three-credit classes [at \$1,800 each]," says Thompson, adding that she does not keep track of how much each faculty member is paid by their home institution.

eCore receives revenue by retaining the tuition dollars from students who remain in eCore courses past the mid-point of each semester. The tuition is gathered at the home institution, and $80 \%$ of this revenue is sent to eCore. "We will invoice the institutions [after mid point of each semester], and they send us that money," says Cahoon.

Regarding the decision-making process for adding eCore courses, Thompson says that initially "it was all done through a general ed committee that got together and decided which courses would be developed. The committee was comprised of Vice Presidents for Academic Affairs and faculty members from the 34 University System of Georgia institutions. We have talked about adding a couple more courses that students and advisors have said they needed, so we would probably work with that same group in developing the new courses, if we decide to do that."

"We have much less flexibility than we do with IDL in terms of making a decision about what courses we can add to eCore," adds Cahoon. "We have had many requests for particular courses, and we have passed those requests up the chain. We would like to develop a few more courses, but it is a very slow process for us to receive approval."

\section{E. Current Enrollments and Growth Prospects}

eCore is starting to grow quickly. Last fall it had 1,300 enrollments, and this fall it has 1,700 enrollments. "It is growing fast in terms of demand," says Cahoon. We just have to bring in new people."

"We will probably need to hire a few full-time eCore faculty members," adds Thompson. "eCore was really designed to be just the core curriculum of the System, so that any institution could build a complete degree online, and students anywhere in the System could take their core curriculum courses through eCore and then go to one of the other institutions to complete their last two years." "I think all of us in this area are kind of making it up as we go along,” Cahoon concludes. 